\title{
A Avaliação da Aprendizagem no Contexto da Reforma Educacional Brasileira $^{1}$
}

\author{
SILZA MARIA PASELLO VALENTE \\ Doutora em Educação pela UNESP/Marília. \\ Docente do Depto. de Educação da Universidade Estadual de Londrina \\ valente@paraisoonline.com.br
}

\begin{abstract}
Resumo
O presente artigo discute, introdutoriamente, questões relativas à avaliação da aprendizagem centrando-se no entendimento de como esta deve se processar. Na seqüência, analisa como a avaliação é compreendida e contemplada nos documentos oficiais, especialmente nos processos avaliativos de larga escala (Saeb e Enem), no Referencial Curricular para a Educação Infantil e nos Parâmetros Curriculares Nacionais dos Ensinos Fundamental e Médio.
\end{abstract}

Palavras-chave: avaliação da aprendizagem , Reforma Educacional Brasileira.

\section{Resúmen}

El presente artículo discute, introductoriamente, cuestiones relacionadas con la evaluación del aprendizado, centralizándose en la comprensión de como ésta debe procesarse. A continuación, analiza como la evaluación está comprehendida y contemplada en los documentos oficiales, especialmente en los procesos de evaluación de larga escala (Saeb y Enem), en el Referencial Curricular para la Educación Infantil y en los Parámetros Curriculares Nacionales de la Enseñanza Fundamental y Media.

Palabras-clave: evaluación del aprendizado, Reforma Educativa Brasileña.

\begin{abstract}
The present article is a preliminary discussion of issues related to learning evaluation and focuses on how this evaluation should be accomplished. It then analyses how evaluation is understood and considered in official documents, especially in large scale evaluation processes like Saeb and Enem, as well as in the Curricular Referential for Pre-Schools and the National Curricular Parameters for Elementary and Secondary Schools.

Key words: learning evaluation, Brazilian educational reform.
\end{abstract}

1 O presente artigo é parte integrante da tese Parâmetros Curriculares Nacionais e Avaliação nas Perspectivas do Estado e da Escola, elaborada sob a orientação do Prof. Dr. Celestino Alves da Silva Jr., no contexto do Programa de Pós-Graduação da UNESP/Marília e defendida em junho de 2002.

Estudos em Avaliação Educacional, n. 28, jul-dez/2003 


\section{AVALIAÇÃO DA APRENDIZAGEM}

A literatura educacional é pródiga no sentido de conceituar a avaliação. Não pretendemos fazer uma revisão dos conceitos existentes, porque não se justifica no presente trabalho. Luckesi (1996, p.33), que se debruça há longo tempo no estudo desse tema, afirma que a definição mais adequada que se encontra comumente estabelece que "a avaliação é um julgamento de valor sobre manifestações relevantes da realidade, tendo em vista uma tomada de decisão". Embora não discordemos de tal definição, no texto mencionado - redigido em 1984 -, Luckesi (1996) alerta para o perigo de sua utilização arbitrária. Doze anos após, o autor publicou outro artigo denunciando que, embora em nossa prática escolar utilizemos a denominação de avaliação, o que praticamos são provas e exames sobre cujos resultados estabelecemos juízos de valor que levam o aluno à exclusão. Diz o autor que, para exercer um papel transformador, que é o cerne da sua existência, a avaliação deveria ser exercitada em outra perspectiva: a do acolhimento, típica de um ato amoroso, como deve ser todo ato de ensino e aprendizagem.

Consideramos que a avaliação, por envolver uma gama de planos epistemológico, político, pedagógico, psicológico, cultural -, talvez seja não só o mais complexo dos aspectos do processo pedagógico, como o seu calcanhar de Aquiles (Valente, 1996), visto que expõe os pontos positivos e negativos, seja do sistema, da escola ou da sala de aula, aí compreendidos professores e alunos. Pode-se dizer que, sendo potencialmente desestabilizadora, na medida em que envolve a comunicação de seus resultados, os quais implicam sucesso ou fracasso dos envolvidos no processo avaliativo, com conseqüente impacto na auto-imagem, a avaliação necessita de ser compreendida e executada com razão e sensibilidade.

Razão - por necessitar de análises e ações fundamentadas em conhecimentos dos campos político, ideológico e pedagógico, os quais fornecem a base, tanto para decidir se será utilizada como um instrumento de libertação ou de opressão, quanto para tomar decisões de índole operacional. Essas dizem respeito a questionamentos, tais como:

- A avaliação será desenvolvida tendo como referência a norma, os critérios ou os objetivos?

- Quais técnicas e instrumentos são coerentes com o processo ensino e aprendizagem desenvolvido nas aulas?

- Como serão elaborados os instrumentos avaliativos? 
- Quais as exigências para a elaboração de instrumentos avaliativos (testes, provas com questões dissertativas, fichas de observação, entre outros)?

- Como deverá ser realizada a correção?

- Como deverão ser demonstrados os resultados das verificações de aprendizagem?

- Qual a maneira mais adequada para comunicar os resultados?

Tais decisões são coletivas, pois se traduzem no Projeto Pedagógico da escola. No entanto, possuem também componentes de decisão individual, visto que cabe ao professor elaborar e aplicar os instrumentos avaliativos, assim como analisar e comunicar seus resultados.

Sensibilidade - porque os resultados de um processo avaliativo são comunicados a pessoas que têm sentimentos atávicos ligados à avaliação como algo negativo. O imaginário coletivo brasileiro, no que se refere ao campo pedagógico, foi profundamente influenciado pela pedagogia jesuítica, a qual estabeleceu as bases da nossa escola. Por essa razão é que se relaciona avaliação muito mais com sentimentos de punição, fracasso, rejeição, humilhação (Luckesi, 1996), do que com sentimentos de autoanálise com vistas à superação daquilo que se apresenta de forma negativa.

Não podemos nos esquecer de que, ao longo da nossa história, a avaliação tem sido um poderoso instrumento de poder e autoridade docente e utilizada muito mais para descobrir e punir o que não se sabe (basta para isto constatar os altos índices de evasão e repetência), do que para valorizar o que se sabe. Portanto, a comunicação dos seus resultados, a forma de proceder após a identificação dos pontos falhos, o acolhimento do aluno com dificuldades e a manifestação de que lhe é possível superar o que hoje está falho são atitudes docentes que permitem um outro olhar sobre a avaliação. É preciso que se entenda que a dificuldade tem um caráter de temporalidade, não é eterna. Todo processo avaliativo envolve um referente, que consiste na norma ou modelo, e se manifesta nos objetivos ou nas competências e habilidades; e um referido, que consiste naquilo que é constatado, medido, apreendido (Rodrigues, 1999). Sordi (1998, p.51-52), discorrendo sobre a avaliação dos cursos de graduação, chama a atenção para esse aspecto: "A mera afirmação de que é necessário avaliar para apreender, manter, aperfeiçoar ou questionar a qualidade do ensino vigente, não dá conta de explicar qual concepção de qualidade de ensino se toma como referente e a pretexto de quê busca-se concretizá-la no cotidiano". Avaliar, portanto, consiste não só na comparação entre o constatado e o desejado, com conseqüente atribuição de valor (juízo de valor) aos dados obtidos, como já explicitado anteriormente, mas, também, 
na percepção, pelo professor, dos aspectos ideológicos, axiológicos, epistemológicos, políticos e culturais subjacentes a todo processo avaliativo.

Entrementes, devemos estar atentos para o fato de que o estabelecimento de um juízo de valor, como afirma Raphael (1998), é um ato complexo, comparável ao método utilizado nos júris: da competência ou da incompetência do professor na coleta e análise dos dados depende a aprovação ou reprovação do aluno. Mais ainda, depende a construção de seu autoconceito, o qual pode ser profundamente comprometido, podendo gerar expectativas de fracasso e incompetência na vida acadêmica. Sentimento que, muitas vezes, é extrapolado para as demais situações existenciais. No documento introdutório dos PCNs de $1^{\mathrm{a}}$ a $4^{\mathrm{a}}$ também há esse alerta: "A avaliação, ao não se restringir ao julgamento sobre sucessos ou fracassos do aluno, é compreendida como um conjunto de situações que tem a função de alimentar, sustentar e orientar a intervenção pedagógica" (Brasil, 1997, p.81). A avaliação, além disso, abrange valores, atitudes, crenças, concepções educacionais, temores e, principalmente, poder. Estar ciente de todos os aspectos envolvidos em um processo avaliativo é o melhor passo, seguramente, para que se possa cumprir o verdadeiro papel da avaliação, qual seja o de possibilitar ao aprendente o fortalecimento dos pontos positivos e a superação dos deficitários.

Em face do arrazoado e sem minimizar a importância das demais dimensões, consideramos ser de suma importância explicitar os referentes de índole epistemológica que sustentam a avaliação do processo ensino e aprendizagem, expressos nos Parâmetros Curriculares Nacionais e nos instrumentos que realizam a Avaliação em Larga Escala. Mesmo porque é imprescindível a coerência dos Parâmetros Curriculares Nacionais com o Sistema de Avaliação da Educação Básica (Saeb), assim como com o Exame Nacional do Ensino Médio.

\section{A AVALIAÇÃO DA APRENDIZAGEM NOS DOCUMENTOS OFICIAIS}

No contexto da Reforma Educacional Brasileira, no que tange à Educação Básica, a avaliação da aprendizagem, em sala de aula ou na ótica das avaliações em larga escala, pode ser entrevista sob duas vertentes. A primeira delas explicitada nas Diretrizes e Referencial Curricular para a Educação Infantil e nas Diretrizes e Parâmetros do Ensino Fundamental. A segunda, aquela constante nas Diretrizes e Parâmetros do Ensino Médio e 
nos processos avaliativos existentes no Sistema Educacional Brasileiro: Saeb e Enem.

$\mathrm{Na}$ primeira vertente, a avaliação é ancorada em objetivos educacionais gerais que se afunilam em função dos diferentes objetos de ensino e aprendizagem, os quais devem servir de parâmetros para ações de caráter eminentemente formativo.

Os documentos citados, relativos à Educação Infantil e ao Ensino Fundamental, são enfáticos ao estabelecer que o propósito da avaliação não é o de aprovar ou reprovar, mas o de acompanhar o processo de desenvolvimento dos alunos, a manifestação de condutas que expressem capacidades de ordem cognitiva, física, afetiva, de relação interpessoal, ética e estética. Para tanto, o professor deve utilizar uma série de técnicas e instrumentos que possam fornecer dados para a análise qualitativa do desempenho dos alunos; a reflexão sobre a própria prática docente; a autoanálise dos estudantes; a realimentação do projeto pedagógico da escola. Nesse sentido, a avaliação deve ser contínua e realizada em todos os momentos do processo ensino e aprendizagem, tendo em cada um deles funções e propósitos diferenciados.

Realizada no início do processo - Avaliação Inicial - fornece ao professor elementos para identificar como estão seus alunos em relação às aprendizagens previstas como necessárias para determinada série ou fase do ciclo. A Investigação Inicial não deve ser pontual nem demorar em refinados diagnósticos. Pretende, tão somente, identificar o ponto de partida real, não o presumido, para o planejamento do professor, ao início do período letivo; e, no decorrer dele, possibilitar que o professor saiba como seus alunos estão antes de abordar novos conteúdos.

Realizada durante o processo - Avaliação Contínua - tem o caráter de acompanhamento, de identificação dos sucessos e insucessos, e, no segundo caso, da identificação de suas causas. É com este permanente olhar avaliativo que o professor adquire elementos para proporcionar experiências que possam levar os alunos a superarem suas dificuldades. Um olhar avaliativo que deve contar com o auxílio de outros olhares que possibilitem uma análise ampliada: o olhar do próprio aluno - autoavaliação -, o olhar da equipe pedagógica da escola, o olhar da família.

Realizada no final do processo - Avaliação Final - tem o propósito de, em determinados momentos, identificar o que o aluno já aprendeu sobre os conteúdos trabalhados. Pode-se afirmar que esta avaliação é uma síntese das demais e constitui um momento em que é estabelecido o juízo de valor com vistas à certificação. Se considerarmos que, como fruto de processos avaliativos mal conduzidos, temos a repetência e a evasão escolares, sobressai a necessidade de que esta avaliação final se valha do 
maior número possível de informações, amparando-se, portanto, nos dados derivados da avaliação contínua.

Contemplando esta perspectiva e levando em consideração as diferentes aptidões dos alunos, os Parâmetros Curriculares Nacionais, referentes ao Ensino Fundamental, assinalam a necessidade de thes possibilitar a utilização dos vários códigos expressivos: pictórico, oral, escrito, gráfico, numérico. E preconizam a utilização de técnicas diversificadas (observação, inquirição, testagem) e distintos instrumentos (escalas de observação, questionários, entrevistas, pesquisas, entre outros). O paradigma avaliativo dos aludidos documentos, embora expresse uma perspectiva construtivista, já que enfatiza a necessidade de o aluno ser o sujeito do processo de construção do conhecimento e considera o erro como elemento constitutivo desse processo, denota e conota procedimentos claramente afeitos à pedagogia dos objetivos, predominante na década de 70 .

Os Parâmetros Curriculares Nacionais referentes ao Ensino Fundamental causam um descompasso epistemológico. Ao explicitarem que os objetivos devem ser estabelecidos em termos de capacidades, remetem seus leitores diretamente a Bloom - embora a produção teórica deste autor não conste nas Referências - mais precisamente à "Taxionomia dos Objetivos Educacionais: domínio cognitivo". As citações a seguir exemplificam a similaridade dos posicionamentos:

"Ainda que seja reconhecida a importância da informação ou conhecimento como produto da educação, poucos professores ficariam satisfeitos em considerá-lo como resultado único ou fundamental do ensino. Necessário é que os alunos demonstrem sua capacidade de fazer algo com o conhecimento adquirido, isto é, que possam aplicar a informação em novas situações e problemas." (Bloom et al., 1983, p.34 - grifos meus)

Os objetivos propostos nos Parâmetros Curriculares Nacionais concretizam as intenções educativas em termos de capacidades que devem ser desenvolvidas pelos alunos ao longo da escolaridade. A decisão de definir os objetivos educacionais em termos de capacidades é crucial nesta proposta, pois as capacidades, uma vez desenvolvidas, podem se expressar numa variedade de comportamentos. (Brasil, 1997, p.67 - grifos meus).

A organização e a avaliação do processo ensino e aprendizagem por objetivos está inserida em um campo conceitual que tem sua gênese em Tyler, na década de 40 (Raphael, 1998; Mezzaroba; Alvarenga, 1999; Vianna, 2000). Para esse teórico, educar consistia em mudar padrões de comportamento, os quais deveriam ser claramente explicitados, a fim de se 80

Estudos em Avaliação Educacional, n. 28, jul-dez/2003 
constituírem em guias, tanto para a avaliação do desempenho dos estudantes, quanto para as tomadas de decisão dos professores, pais, instituição escolar e dos próprios alunos.

Vianna (2000) destaca a importância de Tyler à medida em que este amplia a compreensão da avaliação, permitindo a superação do aspecto restritivo e exclusivo da avaliação da aprendizagem e envolvendo a avaliação curricular. Aponta, também, a influência de Tyler nas obras de Bloom e Hilda Taba, principalmente na elaboração das taxionomias. Uma influência, destacamos, claramente percebida por aqueles que, como nós, tiveram seu processo de formação profissional eivado pela produção teórica dos autores mencionados.

Bloom et al. (1983, p.24), explicitam: "Entendemos por objetivos educacionais formulações explícitas das mudanças que, se espera, ocorram nos alunos mediante o processo educacional; isto é, dos modos como os alunos modificam seus pensamentos, seus sentimentos e suas ações". É devido a tal fato que a leitura dos Parâmetros Curriculares Nacionais, referentes ao Ensino Fundamental, deixa-nos com uma sensação de idéia de déjà $v u$. A impressão é a de que o texto já faz parte do imaginário educacional há muito tempo e, agora, surge travestido em uma outra roupagem, com foros de atualidade.

Tyler, Taba, Bloom, principalmente este último devido à penetração das suas taxionomias dos objetivos educacionais - domínios cognitivo e afetivo -, têm sido alvos de críticas mordazes. Esses juízos partem, muitas vezes, de profissionais que nunca leram nem uma de suas inúmeras obras. No entanto, atuando em cursos de formação continuada, ouço manifestações no sentido de que os professores sentem falta de referenciais para o estabelecimento dos objetivos. A mesma ausência é percebida quando examino provas aplicadas nos diferentes níveis de ensino. Tais evidências ressaltam a falta que faz o conhecimento de taxionomias que possam fornecer aporte teórico a um fazer claramente sedimentado no senso comum, sejam elas da lavra dos autores mencionados, ou não.

Esta constatação leva-nos a lamentar os comportamentos de exaltação ou negação das teorias educacionais. Quando louvadas, faz-se a apropriação muitas vezes reducionista das mesmas e depois se critica a ineficiência dos resultados. Quando negadas, rechaça-se, sem maiores análises, deixando-se de lado contribuições expressivas. Pode-se comparar, de certa forma, o espaço educacional formal com um leilão onde idéias são valorizadas ou depreciadas, devido às injunções do momento e depois, nem se sabe muito bem por que, desprestigiadas ou incensadas.

Tyler, Bloom e Taba são considerados teoricamente comprometidos com a abordagem comportamentalista, principalmente Bloom et al. (1983, 
p.15-16), freqüentemente "acusados" desta ligação, ainda que os autores tenham afirmado:

\begin{abstract}
"Os membros do grupo que trabalharam na taxionomia dedicaram um tempo considerável à tentativa de encontrar uma teoria psicológica que proporcionasse uma base sólida para ordenar as categorias da taxionomia. Revisamos teorias da personalidade e da aprendizagem e fomos incapazes de encontrar uma única perspectiva que, em nosso entender, abrangesse a variedade de comportamentos representados nos objetivos educacionais que experimentamos classificar [...]. É necessária, pois, uma teoria de aprendizagem mais ampla e global do que as que existem atualmente."
\end{abstract}

Apesar dessa manifestação dos pesquisadores, é possível perceber em suas proposições a influência do comportamentalismo, principalmente na elaboração dos objetivos educacionais em termos de comportamentos observáveis. Talvez essa omissão do discurso oficial em relação ao comportamentalismo deva-se ao fato de este ter fornecido sustentação à tendência tecnicista, que não só coincide com um momento histórico de ingrata lembrança aos brasileiros (período da ditadura militar), como é alvo de profundas restrições devido ao seu caráter reducionista. Isto faz com que suas contribuições ao universo educacional sejam omitidas e minimizadas, quando não execradas.

As idéias de Bloom et al. (1983), como é passível de constatação, ainda se fazem fortemente presentes. Basta lembrarmo-nos de que a concepção de avaliação formativa, no tocante à aprendizagem dos alunos, como diz Perrenoud (1999, p.14), tem sua gênese na "pedagogia para o domínio". O referido autor, ao analisar esta mesma situação em relação à Reforma de Ensino Francês, afirma que a abordagem por objetivos não está superada, o necessário é manter-se ciente dos seus excessos. E aponta os elementos desta abordagem que devem ser evitados: behaviorismo sumário, taxionomias intermináveis, excessivo fracionamento dos objetivos, organização do ensino objetivo por objetivo.

Consideramos ser oportuno destacar que as escolas brasileiras, na década de sessenta, apropriaram-se da abordagem por objetivos muito mais na perspectiva de Mager (1976), com sua proposta de objetivos operacionalizados do que na de Bloom et al. (1983), que enfatizavam a necessidade de a escola visar ao desenvolvimento de capacidades e habilidades mentais diferenciadas, buscando proporcionar aos alunos a aquisição de competências para a resolução de problemas.

Já no caso dos Parâmetros Curriculares do Ensino Médio, sucede o contrário: sua leitura propicia-nos uma sensação de superação do vigente, ao estabelecer como metas do processo ensino e aprendizagem as 
competências e habilidades. No entanto, deixa um vazio teórico, com profundos reflexos na prática docente. Primeiramente porque não explicita os conceitos de competência e habilidade e também porque o quadro resumo que consta ao final de cada área e, posteriormente, de cada uma das disciplinas, contempla de forma conjunta competências e habilidades, sem diferenciá-las no corpo do quadro. Chamamos a atenção para o fato de que, ao estabelecer as áreas de conhecimento e, concomitantemente, determinar as disciplinas que delas fazem parte, os PCNs do Ensino Médio levam a uma sensação de descompasso. É como se a ousadia de conceber a construção do conhecimento em áreas - abordagem interdisciplinar do processo de construção do conhecimento, contemplada nas Diretrizes tivesse um retrocesso voltando ao sedimentado paradigma positivista/disciplinar.

Uma das possíveis conseqüências desse descompasso entre a legislação e a realidade escolar é o fato de o professor do Ensino Médio reduzir sua ação pedagógica a objetivos gerais e específicos, por estes fazerem parte do seu imaginário pedagógico. Um reducionismo reforçado pelo Saeb à medida que este, nos descritores que servem de base para a elaboração das questões, funde conteúdos, competências e habilidades. Lendo tais descritores (D) fica difícil, senão impossível, dissociá-los de objetivos específicos, ainda que o Saeb tenha o propósito de avaliar competências e habilidades. Exemplificando:

Matriz de Referência do Saeb/2001:

x Descritores de Língua Portuguesa $-3^{\mathrm{a}}$ série do Ensino Médio:

D6 - Identificar o tema de um texto.

D9 - Diferenciar as partes principais das secundárias em um texto.

D8 - Estabelecer relação entre a tese e os argumentos oferecidos para sustentá-la.

× Descritores de Matemática:

D1 - Identificar figuras semelhantes mediante o reconhecimento de relações de proporcionalidade.

D10 - Reconhecer, dentre as equações do $2^{\circ}$ grau com duas incógnitas, as que representam circunferências.

D6 - Identificar a localização de pontos no plano cartesiano. (Inep, 2002, p.16-22).

Perrenoud (1999a, p.19) adverte: reduzir as competências a objetivos ou considerá-las o mesmo que objetivos, pelo fato de serem elaboradas indicando ações a serem realizadas, pode levar a uma compreensão 
inadequada do conceito de competências. É preciso assimilar que a "pedagogia por objetivos é perfeitamente compatível com um ensino centrado exclusivamente em conhecimentos", enquanto as competências vão além destes. Neste caso, enquanto os objetivos podem ser baseados simplesmente em memória, as competências jamais poderiam ser explicitadas nestes termos.

Perguntamos: nos descritores do Saeb, acima exemplificados, como fazer a diferenciação entre objetivos e competências? Suponhamos que um determinado professor tenha em mãos esses descritores. Como seria possível explicar-lhe que eles se referem a competências e não a objetivos? Esse tipo de análise somente poderia ser realizado a partir das questões das provas, as quais não são disponibilizadas. Percebemos que a contradição, da qual a situação apontada é exemplo, permeia os documentos oficiais gerando perplexidades e desafios para a prática pedagógica.

Embora o Referencial para a Educação Infantil e os Parâmetros Curriculares Nacionais referentes ao Ensino Fundamental façam menção a um processo de ensino e aprendizagem centrado em objetivos; e as Diretrizes e os Parâmetros Curriculares Nacionais do Ensino Médio estabeleçam como norte as competências e habilidades, chamou-me a atenção $o$ fato de não ter encontrado nos documentos oficiais esclarecimentos do porquê dessas abordagens diferenciadas, embora tenha pesquisado insistentemente. Assim como não encontramos explicação para o fato de os Parâmetros Curriculares do Ensino Fundamental estabelecerem objetivos, e o Saeb, que avalia os concluintes das quartas e oitavas séries, competências e habilidades.

Ou seja, o professor planeja em termos de objetivos, e os alunos são avaliados em termos de competências e habilidades, evidenciando incoerência entre os processos de ensino e aprendizagem e de avaliação em nível macro.

Uma possível explicação para o descompasso entre os PCNs dos ensinos Fundamental e Médio pode estar situada nos aspectos enunciados no texto de Silva (1996) que, recorrendo a Bernstein, faz uma análise do continuum da pedagogia nas diferentes etapas de escolarização. Afirma o autor que quanto mais se aproxima do universo do trabalho, mais a pedagogia muda de invisível - preocupada com o processo -, para visível preocupada com os resultados -, tendo necessidade de estabelecer com clareza o perfil do egresso.

Por ser o veículo de estabelecimento dos princípios axiológicos e pedagógicos que possibilitem às instituições escolares vincular o Ensino Médio "com o mundo do trabalho e a prática social, consolidando a preparação para o exercício da cidadania e propiciando preparação básica 
para o trabalho", como disposto no Art. $1^{\circ}$ da Resolução CEB n.3/98 (Brasil, 1999, p.1) , deduzimos, neste caso, que esta seria a função das competências e habilidades do Ensino Médio, estabelecidas em suas Diretrizes e Parâmetros Curriculares. No entanto, permanece sem explicação o fato de alunos da $4^{\mathrm{a}}$ e $8^{\mathrm{a}}$ séries serem avaliados, pelo Saeb, em termos de competências e habilidades.

Outro elemento que merece destaque é o fato de, nos PCNs do Ensino Fundamental, a avaliação ser proposta tendo como referência imediata os critérios de avaliação, ou seja, o aceitável e não os objetivos, os quais devem ser interpretados como indicadores das aprendizagens desejáveis, como explicita a citação a seguir:

"No caso da avaliação escolar, é necessário que se estabeleçam expectativas de aprendizagem dos alunos em conseqüência do ensino, que devem se expressar nos objetivos, nos critérios de avaliação propostos e na definição do que será considerado como testemunho das aprendizagens. Do contraste entre os critérios de avaliação e os indicadores expressos na produção dos alunos surgirá o juízo de valor, que se constitui na essência da avaliação [...] os critérios de avaliação apontam as experiências a que os alunos devem ter acesso e são considerados essenciais para o seu desenvolvimento e socialização [...]. É importante assinalar que os critérios de avaliação representam as aprendizagens consideradas imprescindíveis ao final do ciclo e possiveis à maioria dos alunos submetidos às condições de aprendizagem propostas; não podem, no entanto, ser tomados como objetivos, pois isso significaria um injustificável rebaixamento da oferta de ensino $e$, conseqüentemente, o impedimento a priori da possibilidade de realização de aprendizagens consideradas essenciais." (Brasil, 1997, p.86-87)

Na seqüência, o documento aponta que critérios são indicadores precisos para a identificação das aprendizagens, mas devem ser analisados de forma global e contextual, à luz dos objetivos, que são os orientadores do processo. Portanto, devem ser compreendidos como aprendizagens indispensáveis ao final de um período, que além de poderem se manifestar de diferentes formas, também indicam, quando comparadas aos objetivos e à avaliação inicial, para alguns alunos, avanço; para outros, não.

Embora os Parâmetros apontem para o fato de os critérios não serem considerados definitivos nem definidores, há que se relevar que o salto de qualidade dos critérios para os objetivos, esse ir e vir dialético, exige escolas com equipes pedagógicas bem estruturadas e professores com atitude dialógica em relação aos seus pares. Entre o possível - expresso pelos critérios - e o desejável - contemplado pelos objetivos - há uma lacuna que só pode ser preenchida, se forem realizadas análises críticas que possibilitem identificar os caminhos para a superação do vigente. 
No que tange à avaliação, os Parâmetros do Ensino Fundamental ofertam um cipoal de conceitos difícil de ser desembaraçado pelo professor (será que seus elaboradores tiveram como referência o professor real?). Principalmente, porque este aprendeu que a avaliação deve ter como referência os objetivos. Só que os objetivos, segundo o próprio documento introdutório, expressam capacidades não operacionalizadas que podem se manifestar em inúmeros comportamentos. No entanto, até que ponto este objetivo: "no processo de leitura de textos escritos, espera-se que o aluno saiba selecionar textos segundo seu interesse e necessidade" constante dos PCNs de Língua Portuguesa - Terceiro e Quarto Ciclos - não corresponde a um objetivo específico ou a um critério?

Vamos, agora, tomar como referência os conteúdos desenvolvidos, uma vez que a avaliação sempre se refere ao aspecto o quê avaliar. O que dizem os Parâmetros? Eles apontam para a avaliação dos conteúdos conceituais, procedimentais e atitudinais. O que dizem os objetivos? Tomando os Parâmetros de Língua Portuguesa, Terceiro e Quarto Ciclos, como referência, pudemos identificar que são coerentes com os conteúdos. O que dizem os critérios de avaliação sugeridos? A ênfase é na avaliação dos conteúdos conceituais e procedimentais. Os atitudinais não se constituem, praticamente, em focos avaliativos. O mesmo sucede nos PCNs de Ciências Naturais relativos ao Primeiro e Segundo Ciclos. A conclusão natural é que se não são considerados importantes para serem contemplados nos critérios de avaliação, os objetivos atitudinais tendem a ser desprezados na condução do processo ensino e aprendizagem, reforçando, portanto, uma postura que impregna o ambiente educacional formal: a de relegar a segundo plano a apropriação de valores, atitudes e hábitos, quando não de desconsiderá-la.

\section{CONSIDERAÇÕES FINAIS}

Várias são as perguntas que nos ocorrem ao fazer as constatações explicitadas: como agirá o professor ao receber a solicitação de elaborar seu plano de trabalho tendo como norte o Referencial da Educação Infantil ou os PCNs, sejam eles do Ensino Fundamental ou Médio? Até que ponto o professor se desligará de uma prática pedagógica centrada na definição de objetivos operacionais? Qual a diferença, para ele, entre planejamentos utilizando objetivos gerais e específicos - e projetos, ou mesmo planos de disciplina ou aula, referenciados a competências e habilidades? Se o Saeb avalia os alunos, ao término das $4^{\mathrm{a}}$ e $8^{\mathrm{a}}$ séries, tendo como parâmetros competências e habilidades por que os PCNs do Ensino Fundamental 
referem-se a objetivos? Por que não há uniformidade semântica e coerência entre os processos de aprendizagem e avaliação? Como o professor conseguirá perceber a diferença entre critérios de avaliação e objetivos ao desenvolver sua prática pedagógica?

Estas são questões cujas respostas dependem de como a contradição, inerente a elas, será vivenciada no espaço escolar. Exigem, além disso, por parte dos professores, um olhar crítico-compreensivo tanto das próprias concepções e práticas, quanto dos determinantes da Reforma Educacional Brasileira a fim de que possam, ao mesmo tempo em que são determinados pelas circunstâncias, atuarem no sentido de transformá-las.

\section{REFERÊNCIAS BIBLIOGRÁFICAS}

BLOOM, Benjamin S. et al. Taxionomia de objetivos educacionais: domínio cognitivo. 8.ed. Porto Alegre: Globo, 1983. 179 p.

BRASIL. Secretaria de Educação Fundamental. Parâmetros Curriculares Nacionais: introdução aos parâmetros curriculares nacionais. Brasília, DF: MEC/SEF, 1997.

BRASIL. Conselho Nacional de Educação. Resolução CEB n.3, de 26 de junho de 1988: institui as Diretrizes Curriculares para o Ensino Médio. Brasília, DF: Ministério da Educação, 1999.

INEP. Instituto Nacional de Estudos e Pesquisas Educacionais. Exame Nacional do Ensino Médio - Enem: documento básico. Brasília, DF: Inep, 1999.

INEP. Instituto Nacional de Estudos e Pesquisas Educacionais. Saeb 2001: novas perspectivas. Brasília, DF, 2001. Disponível em: <http:/ /www.www.inep.gov.br>. Acesso em: 02 maio 2002.

LUCKESI, Cipriano Carlos. Avaliação da aprendizagem escolar: estudos, proposições. 3.ed. São Paulo: Cortez, 1996. 180p.

MAGER, R. F. A. A formulação de objetivos de ensino. Porto Alegre: Globo, 1976. 138p.

MEZZAROBA, Leda ; ALVARENGA, Georfrávia Montoza. A trajetória da avaliação educacional no Brasil. In: ALVARENGA, Georfrávia Montoza. Avaliar: um compromisso com o ensino e a aprendizagem, Londrina: Núcleo de Estudos e Pesquisas em Avaliação Educacional, 1999. p.29-81. 
PERRENOUD, Philippe. Avaliação: da excelência à regulação das aprendizagens - entre duas lógicas. Porto Alegre: Artes Médicas Sul, 1999. 183p.

PERRENOUD, Philippe. Construir as competências desde a escola. Porto Alegre: Artes Médicas Sul, 1999a. 90 p.

RAMOS, Cosete. Excelência na educação: a escola de qualidade total. Rio de Janeiro: Qualitymark, 1992. 164p.

Pedagogia da qualidade total. Rio de Janeiro: Qualitymark, 1994.

$257 p$.

. Sala de aula de qualidade total. Rio de Janeiro: Qualitymark, 1995.

225p.

RAPHAEL, Hélia Sonia. Avaliação escolar: em busca de sua compreensão.

São Paulo: Brasiliense, 1998. 172 p.

RODRIGUES, Pedro. A avaliação curricular. In: ESTRELA, Albano; NÓVOA, Antonio (orgs.). Avaliação em educação: novas perspectivas. Porto: Porto Editora, 1999. p.15-76.

SILVA, Tomaz Tadeu da. Desconstruindo o construtivismo pedagógico. In: Identidades terminais: as transformações na política da pedagogia e na pedagogia da política. Petrópolis, RJ: Vozes, 1996. p.213-228.

SORDI, Mara Regina Lemes de. A face perversa da avaliação: elementos para uma leitura da avaliação no projeto neoliberal. RAIES - Revista Avaliação, Rede de Avaliação Institucional da Educação Superior, Campinas, v.3, n.1, p.51-57, 1998.

VALENTE, Silza Maria Pasello. Parâmetros Curriculares Nacionais e Avaliação nas perspectivas do Estado e da Escola. Marília, 2002. 206f. Tese (Doutorado em Educação). Universidade Estadual Paulista, 2002.

25 out. 1996.

O calcanhar de Aquiles. Folha de Londrina, Londrina, Cad.1, p.2,

VIANNA, Heraldo Marelim. Avaliação educacional e o avaliador. São Paulo: IBRASA, 2000. 93p.

Recebido em: agosto 2003 Aprovado para publicação: outubro 2003 